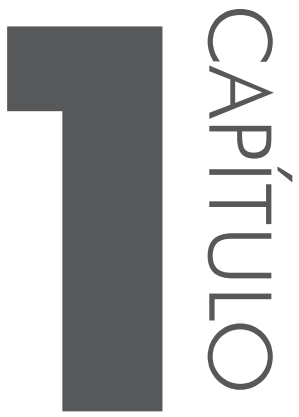

\title{
O PAPEL DA LINGUÍSTICA NA EVOLUÇÃO DOS ESTUDOS GRAMATICAIS NO BRASIL'
}

Maria Eugenia Lammoglia Duarte Universidade Federal do Rio de Janeiro/CNPq

\subsection{INTRODUC̣ÃO}

Neste capítulo, eu me dirijo de modo especial aos alunos de graduação e pós-graduação, que compartilham nosso interesse na descrição da gramática do português brasileiro, à luz de diferentes modelos de estudo da mudança associados a diferentes teorias linguísticas. De maneira muito especial, eu me dirijo àqueles que já atuam no ensino de Língua Portuguesa nos níveis Fundamental e Médio,

A versão original deste texto foi apresentada na conferência de abertura dos trabalhos do VIII Congresso Internacional da Abralin, realizado em Natal, em 2013. Para esta publicação, foram feitas algumas revisões e atualizações. Parte dos itens 1.2 e 1.3 foi desenvolvida em Duarte (2015). 
porque eles se veem diante de livros didáticos (a maioria, infelizmente) que não os ajudam efetivamente a realizar a tarefa para a qual foram preparados (às vezes, com muitas dificuldades).

Quatro pontos principais serão abordados neste texto: em 1.2, eu me refiro a alguns mitos que o desenvolvimento dos estudos gramaticais no Brasil nos permitiu destruir; em 1.3, procuro mostrar como conseguimos desfazer algumas confusões entre teorias para o estudo da mudança e teorias linguísticas, confusões que não percebíamos porque partíamos de alguns pressupostos equivocados; o item 1.4 ilustra, com base em alguns resultados empíricos, o quanto nós conseguimos avançar no reconhecimento da gramática do português brasileiro, chegando a resultados impressionantes relativos à regularidade na distribuição de fenômenos morfossintáticos nos centros urbanos analisados; e, finalmente, em 1.5, eu gostaria de mostrar, inspirada em Kato (2005), o quanto temos avançado na descrição da escrita brasileira contemporânea, produto de um embate entre (a) a gramática que falamos e (b) a gramática que nos serviu (e ainda serve!) de modelo no processo de escolarização. Isso me levará a algumas reflexões sobre a necessidade de direcionar esses resultados para o ensino.

\subsection{ALGUNS MITOS QUE CONSEGUIMOS "NEUTRALIZAR"}

Entre as maiores contribuições resultantes do desenvolvimento dos estudos linguísticos entre nós, eu destacaria a destruição de alguns mitos que sempre rondaram nossa concepção sobre o que é o português do Brasil. Um deles é a ideia de que as diferenças observadas entre a língua nossa de cada dia e as normas repetidas nas gramáticas tradicionais eram explicadas pela "natural" distância entre fala e escrita; ou seja, eram simplesmente resultantes do fato de que a fala é, em geral, mais espontânea, menos planejada, e que a escrita é mais planejada (o que é verdade), ou, pior ainda, que o uso de algumas formas na escrita ou na fala mais monitorada era apenas uma questão de "adequação" linguística. Chegaram mesmo a nos convencer de que o brasileiro usava certas estruturas diferentes das de Portugal pelo seu modo de ser mais suave e dócil ao contrário dos portugueses, que seriam mais ríspidos e rudes. E nós nunca nos perguntávamos se, numa situação informal - uma conversa de cantina ou uma discussão depois de um jogo de futebol, por exemplo - um falante português usaria uma gramática diferente daquela utilizada em outros contextos, se substituiria os clíticos de terceira pessoa por outras estratégias, se passaria de ênclise para próclise, enfim, se mudaria de gramática.

Sabemos hoje que isso é puro impressionismo e que esses exemplos são extremamente infelizes. O que ocorre de fato é que, enquanto os falantes do português europeu usam naturalmente a ênclise, os clíticos de terceira pessoa (o, lhe) 
e o indefinido se, nós, falantes letrados, aprendemos a mudar de gramática num discurso monitorado e na expressão escrita, porque fomos treinados para isso ao longo do processo de escolarização ou através de intenso contato com a escrita, o que um falante não letrado não pode/não sabe fazer, porque não foi treinado para isso. Então, na realidade, nós não ficamos informais quando falamos; nós mudamos de gramática, embora sem conseguir reproduzir com exatidão os modelos que nos são apresentados ao longo do percurso escolar. Retorno a "essa gramática da escrita" no final deste artigo.

E é justamente a propósito dessa visão impressionista de língua que eu gostaria de mencionar o trabalho de Emílio Pagotto (1998), que soube muito bem nos contar como se deu a codificação de uma norma culta escrita no Brasil de fins do século XIX. Passamos de um discurso polêmico sobre o português do Brasil em relação ao europeu - carregado de ufanismo por parte de alguns de cá ou de uma noção de superioridade por parte do colonizador e de outros também de cá, que acreditavam realmente na superioridade da língua lusitana - para um discurso pretensamente científico, que serviu para justificar a adoção do modelo europeu. Faziam parte desse discurso justamente os argumentos baseados em formalidade versus informalidade, chegando mesmo a invocar erradamente a dicotomia saussureana langue e parole. Pagotto $(1998 ; 2013)$ analisou os textos da Constituição do Império, de 1824, e o da primeira Constituição da República, de 1892, e concluiu que a gramática que aparece no texto da primeira metade do século XIX tinha mudado no da segunda metade - em direção à norma lusitana, que seguira um curso de mudanças diferentes a partir do século XVII. Muitas estruturas do português clássico, que persistiam na escrita brasileira e apareciam naquele texto de 1824, tinham desaparecido no de 1892, tal como no português europeu. Com uma diferença: lá, a escrita mudara para incorporar mudanças ocorridas na fala; aqui, a escrita mudou para ficar em conformidade com os novos usos de lá (PAGOTTO, 2013).

Vem daí essa visão ingênua da gramática do português brasileiro, essa ideologia que subjaz os conceitos do "na fala pode; na escrita não". Vem daí o imenso descompasso entre a gramática da fala e a da escrita que se ensina no Brasil, que, sabemos todos, nada tem a ver com a "informalidade" mais característica da fala não monitorada, como a seleção lexical, o uso de gírias, de marcadores discursivos, as hesitações, etc. e a "formalidade" da escrita, fruto do maior planejamento. Essas diferenças têm a ver com gramática mesmo. Nós é que nos sentimos formais quando mudamos de gramática, porque não estamos habituados, no dia a dia, a certas estruturas que reservamos para a escrita ou para certas situações de fala, conscientes de que estamos usando estruturas de outra gramática. Será que algum de nós acredita que um falante português se dá conta de que usa um clítico acusativo, uma passiva pronominal? É claro que ele não percebe isso, porque essas 
estruturas foram adquiridas com sua primeira gramática! (ver discussão a esse respeito em Duarte e Serra, 2015)

Devemos a um grande número de grupos de pesquisa e de pesquisadores individuais espalhados por todo o Brasil a destruição desse mito. E eu não vou, infelizmente, poder mencionar todos eles aqui. Entretanto, não podemos negar que o marco da pesquisa sistemática que nos permitiria compor uma fotografia da gramática do português brasileiro está na chegada de Anthony Naro ao Rio de Janeiro no início dos anos 1970.

À luz do programa de estudo da mudança proposto por Weinreich, Labov e Herzog (2006 [1968]) e usando uma metodologia apropriada para o tratamento estatístico de grande quantidade de dados, as primeiras dissertações orientadas por Naro na Pontifícia Universidade Católica do Rio de Janeiro focalizaram alguns dos mais importantes temas de variação fonético-fonológica e morfossintática que viriam a abrir trilhas para futuras pesquisas, permitindo um melhor conhecimento do verdadeiro português brasileiro.

Enquanto os trabalhos pioneiros de Labov se centraram na variação fonético-fonológica, as primeiras dissertações de mestrado em variação aqui realizadas se concentraram particularmente em fenômenos morfossintáticos, entre os quais as estratégias de relativização (MOLLICA 1977), a representação do acusativo anafórico (OMENA 1978)² e o uso variável de marcas de concordância nominal (Braga e Scherre, cujas dissertações foram defendidas em 1978). Se acompanharmos os estudos empíricos realizados a partir de então, veremos que esses trabalhos pioneiros tiveram uma visão perspicaz de alguns dos mais notáveis traços do português brasileiro. O uso variável de marcas de concordância nominal, por exemplo, que seria ampliado por Scherre na sua tese de doutorado, ainda sob a orientação de Naro, e depois estendido à variação no uso de marcas de concordância verbal, numa longa parceria com o orientador, representa um dos mais bem descritos fenômenos variáveis do português brasileiro e é certamente o único traço da nossa gramática ainda sujeito a forte estigma nos centros urbanos, apesar de os resultados das pesquisas revelarem que todos, uns mais outros menos, perdemos marcas de concordância aqui e ali. Além disso, pesquisas recentes revelam aumento no uso de marcas, independentemente do número de anos de frequência escolar (cf. Naro e Scherre, 2003, entre outros). Estamos diante de um marcador social, que separa, de maneira absolutamente injustificável, os brasileiros que vivem nos meios urbanos. Esse é um dos mitos mais difíceis de combater, apesar da divulgação de pesquisas diversas e vozes veementes contra o preconcei-

2 É dessa mesma década de 1970 a tese de Votre (1978) sobre fenômenos fonético-fonológicos, que viriam a ganhar terreno a partir da década de 1980 sem que, no entanto, a atenção sobre fenômenos morfossintáticos fosse abandonada. 
to linguístico, que têm em Marcos Bagno e Marta Scherre alguns de seus maiores representantes.

Voltemos à dissertação de Nelize Omena, que analisou a fala de adultos em fase de alfabetização, usando a amostra Mobral, organizada por Lemle e Naro (1977). Sua análise mostrou que o clítico acusativo de terceira pessoa já não fazia parte da gramática do brasileiro (e aqui estamos usando o conceito de gramática que a linguística nos ensinou); Omena (1978) não atestou qualquer ocorrência do clítico acusativo, o que nos revelou que o brasileiro não letrado realizava as funções acusativas anafóricas com um pronome nominativo ou mais frequentemente por meio de uma categoria vazia (referida por Omena como anáfora zero dentro do quadro funcionalista que orientou a pesquisa, e hoje tratada mais comumente como objeto nulo). Essa forma de realização do acusativo anafórico, aliás, muito mais frequente do que o uso do pronome nominativo em função acusativa, nunca foi notada pelos nossos gramáticos normativos, porque não apresentava saliência (nem aos seus ouvidos nem "aos seus olhos"...). Isso fica evidente na insistente condenação do uso do "pronome tônico", como se este fosse frequente. Ledo engano! Frequente é o apagamento do objeto anafórico!

Ficou claro em análises posteriores, sempre na esteira do trabalho pioneiro de Omena, que o clítico acusativo aparecia de maneira muito modesta, quase inexpressiva, na fala dos letrados (ver em Duarte e Ramos (2015) um mapeamento dos trabalhos realizados no país sobre as realizações do acusativo anafórico no português brasileiro). $\mathrm{O}$ que esses trabalhos revelam é que o contato com a gramática da escrita não é suficiente para modificar de modo substancial o desempenho do letrado brasileiro. Ele só vai efetivamente lançar mão desses traços aprendidos via escola na fala muito monitorada (por aqueles que têm esse tipo de treinamento) ou quando usa a escrita, e, ainda assim, de modo muito parcimonioso e em certos contextos estruturais (cf. DUARTE, 2013a,b). Mais um mito destruído!

O trabalho desenvolvido por Naro e seus alunos se espalhou por diversas universidades em diferentes regiões do país, fosse através do intercâmbio de membros do seu grupo de Pesquisa PEUL - Programa de Estudos sobre o Uso da Língua - com outras instituições, como a Universidade Federal de Santa Catarina, a Universidade Federal da Paraíba, de Alagoas, entre várias outras, para a formação de amostras e a aplicação do modelo teórico e da metodologia variacionista, fosse através da formação de alunos que vinham de outras universidades para cursar seu doutorado sob a orientação de Naro.

A amostra de fala constituída por Naro e seu grupo do PEUL, conhecida como Amostra Censo - que incluía falantes com quatro níveis de instrução, dos primeiros segmentos do Ensino Fundamental ao Ensino Médio - viria a contribuir para compor um quadro mais completo da fala carioca, que já contava, num extremo, com entrevistas feitas com adultos em fase de alfabetização, do antigo 
Mobral - a mencionada amostra organizada por Lemle e Naro - e, no outro extremo, com uma vasta documentação de entrevistas com falantes com curso superior completo, parte do projeto nacional NURC - Norma Urbana Culta, iniciado por Nelson Rossi da UFBA e Celso Cunha da UFRJ. O Projeto NURC idealizado para documentar a norma objetiva de uma variedade "prestigiada" do português brasileiro nas cinco capitais mais populosas e representativas durante os anos 1970, com mais de um milhão de habitantes (Recife, Salvador, Rio de Janeiro, São Paulo e Porto Alegre), seria mais tarde a base de um grande projeto de pesquisa, reunindo estudiosos de várias universidades brasileiras, de diferentes correntes teóricas, sob a liderança de Ataliba de Castilho. ${ }^{3}$

Não tenho conhecimento de outro país que tenha conseguido esse feito: reunir um grupo tão diverso em torno da descrição de um corpus oral. $\mathrm{O}$ trabalho realizado por esse grupo, ao longo de vinte anos, somado aos desenvolvidos com outras amostras por todo o país com base na fala de indivíduos cultos, viria nos confirmar que não há diferenças significativas entre as variedades cultas e as chamadas variedades populares do português brasileiro, exceto, naturalmente, pelo maior ou menor índice de uso de marcas de concordância, de que trataremos o item 1.4. Confirmava-se a destruição de mais um mito!

\subsection{TEORIAS DE MUDANÇA E TEORIAS LINGUÍSTICAS}

Outra contribuição, neste caso específico, advinda do desenvolvimento dos estudos sociolinguísticos, foi desfazer algumas confusões entre teorias de mudança e teorias da linguagem.

Em primeiro lugar, desde os primeiros trabalhos orientados por Naro nos anos 1970, a questão colocada por Beatriz Lavandera em 1978 sobre os limites de uma variável sociolinguística, pondo em questão o valor de verdade de uma variável sintática, já não devia constituir problema entre nós desde sua proposição. Afinal, o mencionado trabalho de Mollica, sobre as estruturas de relativização, defendido em 1977, e o de Omena, em 1978, já bastavam para refutar qualquer dúvida acerca das variáveis morfossintáticas, pois elas trabalharam com variáveis sintáticas perfeitas: e, afinal, se a mudança pressupõe formas em competição durante algum tempo (geralmente, um longo período), como pensar que a mudança sintática se efetivaria sem passar por esse estágio indispensável? Apesar disso, ainda hoje é comum vermos enfatizada, em teses e dissertações, a questão colocada por Lavandera, sem que se defenda a legitimidade das variáveis morfossintáticas com base nos estudos de mudança que nós já empreendemos e continuamos a desenvolver.

Entre as publicações, contam-se Jubran e Koch, 2006; Ilari e Moura Neves, 2008; Ilari, 2014;

2015; Kato e Nascimento, 2009; 2015; Abaurre, 2013. 
Um outro equívoco que acabou por se desfazer (embora ainda não esteja claro para alguns) consistia em confundir a Teoria da Variação e Mudança, normalmente referida como Sociolinguística Variacionista, com uma teoria linguística e não a identificar como uma teoria para o estudo da mudança linguística. Parece que os trabalhos clássicos em variação e mudança que chegaram até nós, como a dissertação de mestrado e a tese de doutorado de Labov, ambos envolvendo variáveis fonético-fonológicas, nos deram a falsa impressão de que a Teoria da Variação e Mudança dava conta de realizar um estudo que desvendasse os caminhos de um processo de mudança sem se sustentar numa teoria linguística. Não é possível levantar hipóteses de trabalho, caracterizar as variantes em competição, elencar grupos de fatores estruturais em torno de um fenômeno variável sem lançar mão de uma teoria da linguagem. ${ }^{4}$

Ora, o primeiro problema colocado pelo modelo teórico de estudo da mudança proposto por Weinreich, Labov e Herzog (2006 [1968]) é o das restrições (tradução de constraints) - quais são os fatores estruturais e sociais que facilitam ou refreiam implementação de uma nova variante no sistema linguístico? Onde buscar esses fatores estruturais? Numa teoria linguística que melhor atenda a busca de respostas para confirmar ou infirmar as hipóteses do pesquisador. No caso de uma análise acerca de um fenômeno fonético-fonológico, "dependendo do processo a ser explicado, podemos usar o modelo Estruturalista, a Geometria de Traços, que decorre da Fonologia Autossegmental, a Fonologia Prosódica, a Fonologia Lexical, a Teoria da Otimidade, que já tem desdobramentos na Fonologia Estocástica" (Dermeval da Hora, comunicação pessoal). Labov, por exemplo, se utilizava da fonologia de base gerativista desenvolvida por Halle (1962) e Chomsky e Halle (1968), ainda que esse uso não estivesse sempre explicitado como parte do componente gramática que sustentava as análises.

Como investigar a implementação da mudança? Esse "problema”, que reúne a origem e a propagação da mudança (tradução do original actuation problem), não se responde sem um bom elenco de restrições levantadas a partir de uma ou mais de uma teoria linguística. Como buscar resposta para outra questão que é tão cara ao modelo de mudança variacionista (e a qualquer outro modelo de estudo da mudança!)? - como um novo traço se encaixa no sistema linguístico e social (tradução para o embedding problem)? Se eu não tenho uma teoria linguística que me permita entender o que levou uma nova forma a se instalar no sistema e que efeitos a sua instalação provocou - e isso é o que significa "encaixamento

4 Pagotto (2006), que faz um percurso exemplar na aplicação da Teoria da Variação e Mudança, mostrando todas as dimensões não linguísticas que esse estudo pode contemplar, é um dos raros autores que mostram de modo cristalino a onipresença do componente gramatical na aplicação do modelo. 
da mudança" - minha pesquisa pode correr o risco de ficar limitada a uma série de tabelas com a distribuição de valores percentuais e pesos relativos para umas e outras formas variantes, sem relacionar o fenômeno em estudo a outros. Não custa lembrar que Weinreich, Labov e Herzog (2006 [1968]) dizem que os linguistas devem desconfiar de interpretações para a mudança que deixem de levar em conta seu encaixamento numa matriz estrutural e de identificar outras mudanças associadas a ela de uma forma não acidental.

Não é tarefa fácil identificar a origem da mudança (segundo Labov (1994), uma possível explicação para a entrada de uma nova forma sempre leva a outra pergunta). Entretanto, se_tivermos uma teoria linguística que guie ou ilumine o caminho para identificar a propagação da mudança e as pegadas deixadas por ela (ou seus efeitos colaterais, isto é, o aparecimento de novos traços decorrentes de uma dada mudança efetivada no sistema), será possível acompanhar seu percurso e seus efeitos no sistema, e, até mesmo, predizer novas mudanças.

São inúmeros os exemplos do encaixamento estrutural da mudança no português brasileiro. Um deles pode ser visto na efetiva inserção de você como legítimo pronome de segunda pessoa no nosso quadro pronominal, produzindo as combinações mais diversas com formas oblíquas átonas e tônicas do quadro de segunda pessoa, representada antes apenas pelo pronome $t u$, como têm mostrado os estudos de Célia Lopes e seus orientandos e parceiros (cf. LOPES e CAVALCANTE, 2011); ou os efeitos da gramaticalização de a gente, como nos mostram Omena (1986) e Vianna e Lopes (2015), entre muitos outros. A tendência a realizar foneticamente o sujeito pronominal de referência definida (DUARTE, 1995, 2003; SILVA, 2003) no nosso sistema foi outra mudança que não ficou impune! Essa mudança em curso é atestada pelo preenchimento do sujeito de referência indeterminada, pelo aparecimento de estruturas de sujeito deslocado à esquerda, ausentes nas línguas de sujeito nulo ocidentais, e novas consequências estão sendo observadas e reinterpretadas à luz da teoria linguística que um ou outro pesquisador adota (cf. os trabalhos reunidos em Duarte 2012a, que buscam evidências do “encaixamento" à luz da Teoria de Princípios e Parâmetros). ${ }^{5}$

Por que nunca atentamos para tal fato? Por que tantas pesquisas sociolinguísticas ainda hoje apresentam no quadro teórico os fundamentos da Teoria da Variação e Mudança Linguística (que consistem na postulação de que a variação é inerente ao sistema e ocorre de maneira ordenada, que as forças que atuaram no passado são as mesmas que atuam no presente, que apontam as questões a serem respondidas num estudo sobre a mudança, etc), mas nunca explicitam o

\footnotetext{
O mais importante é que as interpretações, advindas de diferentes teorias linguísticas, longe de se contradizerem, são complementares, permitindo uma ampla visão das novas estruturas decorrentes da mudança e sua inserção no contexto discursivo, por exemplo.
} 
fenômeno linguístico em foco nem a teoria linguística de que a pesquisa se servirá para pôr em prática o modelo de mudança. Isso é indispensável para formular hipóteses, levantar os grupos de fatores estruturais, acompanhar a implementação e buscar evidências do encaixamento de uma nova forma no sistema. Parece que o uso de uma descrição gramatical foi assumido como um pressuposto, uma coisa tão óbvia que não precisava ser explicitada, tal como se fazia nos trabalhos sobre a variação fonético-fonológica.

Essa associação indispensável entre um modelo de mudança e uma teoria linguística fica muito clara no artigo de Maria Helena de Moura Neves, intitulado "Estudos Funcionalistas no Brasil", publicado em 1999, no volume 15, da revista Delta, em homenagem aos 30 anos da Abralin. Ao traçar o panorama dos estudos sociolinguísticos realizados no âmbito do Projeto Peul, a autora sempre menciona a corrente funcionalista utilizada por este ou aquele autor. Ou seja: nenhuma pesquisa sociolinguística (de variação e mudança) realizada pelos pesquisadores do Projeto Peul e relatada pela autora foi realizada sem a associação com uma teoria linguística funcionalista, fosse de correntes europeias, fosse de correntes americanas. E isso não escapou à autora.

Entretanto, se a associação da teoria variacionista (como modelo de estudo da mudança) com teorias funcionalistas (como teoria linguística) passou quase despercebida, o mesmo não ocorreu quando a associação se deu com um modelo formal. Fernando Tarallo percebeu muito cedo o que era um modelo de estudo da mudança e o que era uma teoria linguística. E percebeu que sua perspectiva de trabalho, fundada na sintaxe comparativa, não podia prescindir do quadro da Teoria de Princípios e Parâmetros (CHOMSKY, 1981; 1995). Rizzi, em um texto não publicado de 1988, intitulado "The new comparative syntax: principles and parameters of universal grammar", que apareceu mais tarde num livro organizado por Liliane Haegeman, intitulado The new comparative syntax, de 1997, afirma que

a teoria de parâmetros tem um importante potencial explanatório em relação à mudança linguística, um potencial que os linguistas começaram a explorar em torno dos últimos cinco anos (Lightfoot 1991; Roberts 1992). Se uma propriedade P diretamente ligada a um determinado valor paramétrico muda no curso da história de uma língua, nós podemos predizer que outra propriedade dedutivelmente relacionada a $\mathrm{P}$ mudará também ${ }^{6}$ (RIZZI, 1997: 277).

6 "The theory of parameters has an important explanatory potential with respect to language change, a potential that linguists have stated to exploit in the last five years or so (Lightfoot 1991; Roberts 1992). If a property $P$ directly linked to a given parameter value changes in the course of the history of a language, we predict that the other properties deductively linked to $\mathrm{P}$ will change as well.” (RIZZI, 1997:277). 
Estava aí um caminho que permitiria fazer as correlações entre mudanças aparentemente independentes, ou seja, perseguir o "encaixamento" da mudança, ou até mesmo rever certos traços atribuídos a um determinado valor paramétrico. Estava aí a clara indicação de que a marcação do valor de um parâmetro da gramática universal pode mudar e é o que temos mostrado há já bastante tempo em relação ao português do Brasil.

Esse famoso casamento entre um modelo teórico de estudo da mudança e uma proposta teórica de descrição da sintaxe das línguas humanas foi proposto por Tarallo em 1987 e formalizado por Tarallo e Kato, em artigo publicado originalmente em 1989 e reeditado em 2006 na revista Diadorim, do programa de Pós-Graduação em Letras Vernáculas da UFRJ. Não me detenho aqui às críticas que essa associação recebeu (remeto o leitor a DUARTE, 2015a); acho mais importante relatar que os primeiros frutos colhidos desde a formalização do casamento foram reunidos e apresentados por Mary Kato em mesa-redonda durante um seminário organizado por Dermeval da Hora, na UFPB, em 1997, e publicados em Hora e Christiano (1999). O texto de Mary Kato, intitulado "Os frutos de um projeto herético: parâmetros na variação intralinguística”, não deixa dúvidas quanto à aplicabilidade do modelo - analisar e relacionar um conjunto de mudanças superficiais observadas no português brasileiro a uma mudança mais ampla na remarcação do valor de alguns parâmetros da gramática universal à luz do modelo da Teoria da Variação e Mudança.

E os estudos prosseguem; o casamento já não precisa de tantas justificativas, e os resultados só confirmam o que Tarallo não pôde testemunhar em sua plenitude. A tradução de W, L \& H, feita por Marcos Bagno e publicada em 2006, é precedida de um prefácio de Carlos Alberto Faraco, que orienta a leitura desse clássico, situando-o no seu momento histórico, e é seguida de um artigo, à guisa de posfácio, que eu tive a honra de escrever em parceria com Maria da Conceição de Paiva, colega do Departamento de Linguística da UFRJ. Nesse artigo, fazemos um balanço parcial da herança da aplicação desse programa de estudo da mudança na linguística brasileira, sem deixar de mencionar as diversas teorias linguísticas associadas necessariamente à sua aplicação.

A depender do ângulo pelo qual se quer estudar um fenômeno sintático de mudança em curso, a utilização do quadro de Princípios e Parâmetros da Teoria Gerativa é não só desejável, mas necessária. Portanto, assim como é lamentável ver que até hoje a questão levantada por Beatriz Lavandera continue sem uma resposta firme por parte de quem estuda a mudança sintática no Brasil, também é lamentável ver um modelo de mudança confundido com uma teoria linguística em trechos lidos em dissertações e teses variacionistas, tais como "a teoria variacionista, ao contrário do estruturalismo e do gerativismo, se preocupa com a língua em uso". 
Em primeiro lugar, é preciso insistir no fato de que a teoria de mudança variacionista não faz parte do mesmo conjunto de que fazem parte as teorias linguísticas - o estruturalismo, o funcionalismo em todas as suas vertentes, o gerativismo, em todas as suas versões, etc.). A teoria variacionista, é um modelo de estudo da mudança e, portanto, só pode ser comparada a outros modelos de estudo da mudança, como, por exemplo, o modelo proposto por Kroch (1989) e trabalhos posteriores, que se propõe estudar a mudança com base na própria Teoria Gerativa e que, ao contrário da Teoria da Variação, vê as formas variantes como pertencentes a gramáticas distintas, que entram em competição, até que uma vença a batalha. Enquanto ao gerativista interessa a origem da mudança, ao variacionista interessa sua propagação ao longo do tempo (cf. MARTINS, COELHO; CAVALCANTE, 2015). No entanto, qualquer modelo de estudo da mudança terá de lançar mão de dados reais, da língua em uso, venham esses dados da fala ou da escrita de outras sincronias.

Aliás, isso nos leva a outra afirmação equivocada, que vamos, aos poucos, eliminando: "a teoria gerativa não está interessada em dados reais; só trabalha com a gramática do falante ideal". Como é, então, que os gerativistas estudam a aquisição da linguagem? Como é que os gerativistas estudam a mudança linguística? É claro que há, entre os gerativistas, aqueles que se interessam por análises formais e não precisam de um conjunto exaustivo de dados para desenvolvê-las. Mas quem busca acompanhar a aquisição e a mudança não pode prescindir de dados reais e robustos!!!!. Basta ver o importante trabalho sobre aquisição desenvolvido por Ruth Lopes (2003, entre outros), dentro da perspectiva formalista, e por Christina Abreu Gomes (2013), sobre aquisição de variação estruturada, à luz de modelos multirrepresentacionais, entre tantos outros, e o trabalho realizado por discípulos de Tarallo e Kato e por Charlotte Galves, que vêm desvendando, juntamente com seus orientandos e colaboradores, "as gramáticas do português”, com base numa grande amostra, com anotação sintática, que abarca dos séculos XVI a XIX o corpus Tycho Brahe, disponível na internet. Entre os mais jovens gerativistas que sabem o valor dos dados reais e não abrem mão deles para seus trabalhos, podemos citar Sílvia Cavalcante, da UFRJ, Juanito Avelar, da Unicamp, Marco Antônio Martins, da UFSC, entre tantos outros, cujo trabalho tem permitido generalizações empíricas e formais importantíssimas.

Aliás, parece que esse período de polêmicas envolvendo empirismo versus racionalismo passou. Prova disso é o projeto da Gramática do Português Culto Falado no Brasil, a que já me referi. Os resultados de seu desenvolvimento, publicados ao longo do período de duração do projeto, são a prova de que uma análise de dados reais precisa de um suporte teórico adequado ao estudo do fenômeno em foco. Vejam os resultados consolidados nos volumes já publicados sobre os marcadores discursivos, sobre as classes de palavras, sobre a construção 
da sentença e a construção do vocábulo (cf. Nota 3). A leitura dos capítulos que compõem esses volumes deixa ver a coerência teórica que subjaz a um trabalho de alta qualidade e põe em relevo a força da linguística brasileira.

Um outro projeto, mais uma vez capitaneado por Ataliba de Castilho, o Para a História do Português Brasileiro, continua a prestigiar a descrição de amostras reais - aliás, de que outra maneira nós poderíamos tentar desvendar os caminhos percorridos na formação do português brasileiro? Mais uma vez, temos grupos de pesquisadores de vários estados, que utilizam um modelo de mudança - alguns o modelo variacionista (que vê as formas variantes como parte de uma mesma gramática); outros, modelos formalistas (que acreditam que as formas variantes pertencem a gramáticas diferentes), mas todos eles, sem exceção, utilizam uma teoria da linguagem - sejam teorias funcionalistas, sejam teorias formalistas, a depender do fenômeno investigado e da orientação da pesquisa. Mencione-se ainda a preocupação em buscar unir a história social com a história linguística, condição para a interpretação dos fenômenos e sua implementação, seguindo a tradição iniciada entre nós pela saudosa Rosa Virgínia e hoje continuada por Tânia Lobo e sua equipe do Prohpor na UFBA, e por Dinah Callou e sua equipe no Rio de Janeiro.

\subsection{O PORTUGUÊS BRASILEIRO FINALMENTE DESVENDADO}

Depois de quase quarenta anos de estudos realizados em todo o país, é possível traçar uma rica fotografia sociolinguística da fonologia e da morfossintaxe brasileira e inferir princípios mais gerais que restringem a variação, mostrando como diferentes processos estão relacionados. É com base nesses estudos que nós podemos afirmar que os traços mais notáveis que distinguem o português do Brasil diatopicamente são aqueles relacionados à prosódia (CUNHA e SILVA, 2015) e à realização de alguns segmentos vocálicos (BRANDÃO, 2015) e consonantais (CALLOU, 2015). Um grande número de processos fonológicos, entretanto, tem uma distribuição muito regular pelo país, tais como a redução do ditongo [ey] diante de fricativas e da vibrante simples; o apagamento do rótico em coda silábica, particularmente em posição final de infinitivos, mas, aparentemente, o processo já se espalha para a posição final em nomes e para as sílabas mediais. E, nesse sentido, o desenvolvimento dos estudos de dialectologia tem trazido imensa contribuição - veja-se o Projeto AliB, sob o comando de Suzana Cardoso, Jacyra Mota, Vanderci Aguilera e muitos outros (cf. MOTA e CARDOSO, 2015).

No que se refere a fenômenos morfossintáticos, entretanto, os resultados, como eu disse antes, indicam uma distribuição bastante regular. Excetuando diferenças regionais apontadas no sistema de tratamento (SCHERRE et al., 2015) e no sistema de reflexivos (DUARTE e RAMOS, 2015), inúmeras publicações com resultados 
consolidados para as variedades populares e cultas em inúmeras regiões do país não deixam dúvida sobre isso (sobre a fala carioca em suas variedades "popular" $\mathrm{e}$ “culta”, cf. SILVA; SCHERRE (1996), LEITE; CALLOU (2002), respectivamente).

Que aspectos da história externa poderiam ajudar a entender essa regularidade na nossa morfossintaxe? Parece que a polarização à qual Dante Luchesi vem se referindo há já bastante tempo deve ser relacionada particularmente à variação no uso de marcas de concordância, pelo menos nas áreas urbanas. $\mathrm{O}$ próprio autor, num recente panorama sobre a polarização sociolinguística no Brasil (cf. LUCHESI, 2015), distingue processos de variação e mudança que atingem todos os segmentos da sociedade brasileira na mesma direção daqueles que tomam direções opostas, separando segmentos de classe alta e média daqueles que se encontram na base da pirâmide social. Considerando que o nível de educação formal tem sido a variável social mais frequentemente utilizada nos estudos variacionistas, nós poderíamos dizer que a maioria dos fenômenos analisados tem distribuição regular nos centros urbanos independentemente do número de anos de permanência na escola. Apenas a frequência no uso de marcas de concordância parece mais sensível ao nível de escolaridade. Mas vejam-se resultados recentes de Naro e Scherre (2003) e, entre inúmeros outros, Brandão e Vieira (2012), Vieira e Bazenga (2013), Brandão (2013), Scherre e Duarte (no prelo), que mostram significativo aumento no uso de marcas de concordância nominal e, principalmente, verbal.

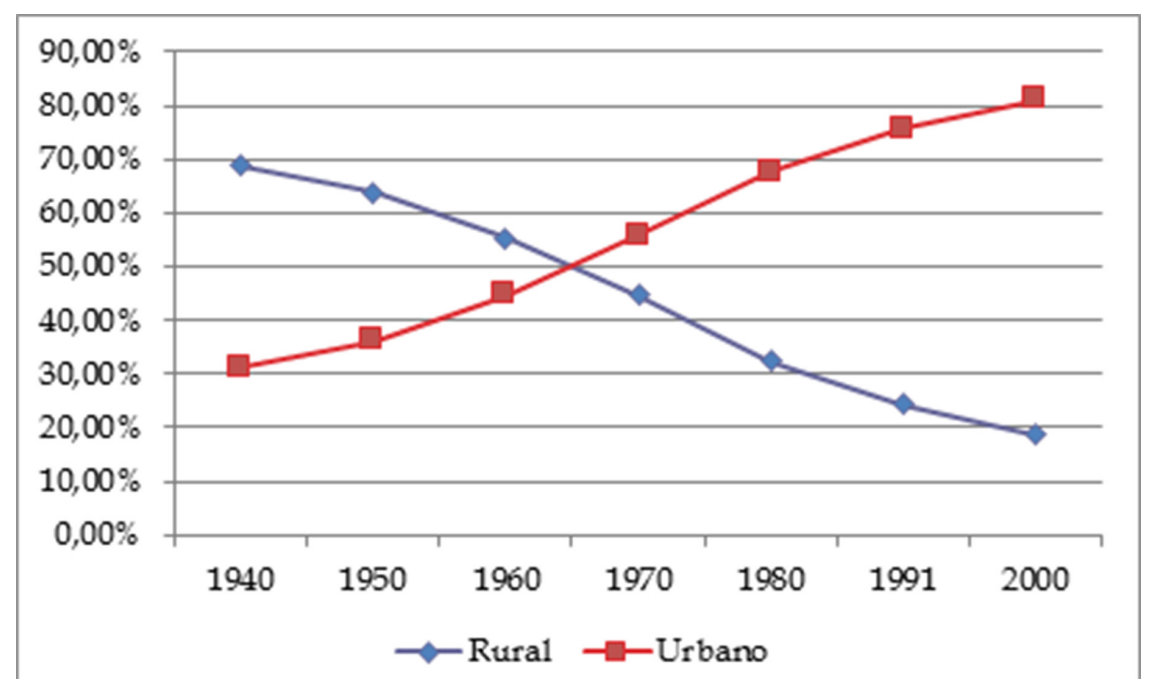

Figura 1.1 Êxodo rural no Brasil em 60 anos.

Fonte: IBGE, censo demográfico 1940-2000.

Mantendo em mente os fatores internos até aqui referidos, um fator externo que talvez pudesse nos ajudar a entender essa distribuição regular dos fenômenos 
morfossintáticos no português brasileiro em tempos mais recentes poderia ser a sucessão de fluxos migratórios do campo para as cidades a partir de meados do século XX. Até a primeira metade do século passado, o Brasil era um país predominantemente rural, com uma população urbana em torno de $30 \%$ nos anos 1940, enquanto $70 \%$ da população se concentrava na área rural. Chegamos a $2000 \mathrm{com}$ uma inversão notável: $20 \%$ da população no campo e $80 \%$ nas cidades:

Foge aos limites deste capítulo detalhar os diversos fluxos migratórios que ocorreram a partir dos anos 1940 ou discutir as consequências sociais provocadas por eles, mas é impressionante ver que a movimentação se deu em direção a todas as regiões do país pelas mais diversas razões. Os primeiros fluxos migratórios ocorreram a partir da década de 1950 de áreas rurais do Nordeste para os estados do Sudeste, particularmente São Paulo e Rio de Janeiro. Movidos por desemprego, secas, inundações, esses migrantes foram atraídos pela industrialização em busca de melhores condições de subsistência. Outro fluxo ocorreu no final dos anos 1950, do Nordeste e do Sudeste (especialmente de Minas Gerais) em direção ao Centro-Oeste, atraído pela necessidade de mão-de-obra para ocupar Brasília e para trabalhar na construção de rodovias, ferrovias e na agricultura. Uma terceira onda levaria nordestinos para a Amazônia em busca de trabalho na mineração, na extração de madeira e na criação de gado como pequenos fazendeiros. Finalmente nas décadas de 1960 e 1970, a expansão da agricultura atrairia migrantes do Sul e do Sudeste para o Centro-oeste e o Norte. Eram levas de pequenos fazendeiros e trabalhadores rurais que ali se estabeleceram.

Isso me faz voltar ao começo deste artigo: só mesmo a partir do desenvolvimento dos estudos linguísticos, pudemos entender o que é o português brasileiro, este que é construído durante a aquisição (patrimônio de qualquer cidadão brasileiro exposto a uma comunidade de fala) e este português da escola, tão diferente, que chegou a intrigar o Drummond estudante, que percebeu a distância entre aquela língua fácil de falar e de entender e a outra - mistério! Parte do verso final no poema "Aula de português", de Drummond, foi usada por Rosa Virgínia para dar título ao seu livro de 2004, O português são dois... (MATTOS e SILVA, 2004). A autora chamava a atenção para a existência de uma nova gramática, divergente do padrão tradicional, e pedia que ela fosse difundida pelo ensino de português no processo de escolarização.

Foi exatamente esse produto do descompasso entre a fala "na ponta da língua” e aquelas regras incompreensíveis que levou Mary Kato a afirmar que o português são três!!! Sim, esse embate entre uma Gramática Internalizada (nossa primeira língua) e um conjunto de normas baseadas na gramática lusitana de fins do século XIX (a segunda gramática!) produziu uma terceira. A nossa escrita contemporânea não reflete nem exatamente a nossa fala nem exatamente a gramática que serviu de modelo ao ensino: tem traços de uma e de outra e até mesmo 
alguns que não estão nem numa nem noutra. Em seu artigo "A gramática do Letrado", de 2005, Mary Kato compara a aquisição dessa escrita à aprendizagem de uma L2 e discute como se dá o acesso a traços que ocupam uma periferia da nossa gramática nuclear, que contém elementos de outras sincronias (a depender do contexto social em que se encontra um indivíduo, esses traços podem vir das histórias que ouve, das canções, religiosas ou não, que aprende, dos provérbios que repete tantas vezes sem entender certas palavras ou expressões); esses traços, muitas vezes arcaizantes, são ativados durante o processo de letramento no contato crescente com a escrita. A recuperação desses elementos, como comentamos aqui, fica mais restrita à escrita e é apenas parcial, o que nos permite supor que se trata de fato de uma terceira gramática.

E isso nos leva ao último ponto que eu gostaria de levar especialmente aos alunos e aos que atuam na área de linguística: o desenvolvimento dos estudos linguísticos tem nos permitido desvendar essa gramática da escrita brasileira contemporânea. São inúmeros os trabalhos comparativos que investigam como se dá o processo de aquisição e desenvolvimento dessa gramática, analisando a produção de alunos ao longo do processo de escolarização; outros investigam qual é a gramática da escrita veiculada pela imprensa de circulação nacional e daquela que está em nossos artigos, teses e dissertações. Esses resultados apontam para uma gramática heterogênea, variável, na qual identificamos: 1) traços da fala que já se implementam na escrita, em geral as formas menos salientes sintaticamente e, portanto, menos sujeitas a críticas; 2) traços já extintos da fala, que são de maneira curiosa recuperados, ainda que parcialmente, além de algumas inovações (cf. os capítulos em MARTINS; TAVARES (2013), e em MARTINS, VIEIRA; TAVARES (2014)).

A verdade é que colocamos os clíticos de maneira assistemática, às vezes contrariando ao mesmo tempo a nossa própria L1 e a gramática que serviu de modelo ao ensino; perdemos os clíticos para referência à terceira pessoa (o acusativo, o dativo e o indefinido) e, quando os recuperamos na escrita, não é raro trocarmos um pelo outro - o acusativo pelo dativo e vice-versa - não porque não fomos bons alunos, mas porque não temos mais intuição sobre eles. Assim como a inserção de você no nosso quadro pronominal provocou a combinação de formas do paradigma de $t u$ com o de você, assim também a nossa indecisão entre favorecê-lo e favorecer-lhe, entretê-los e entreter-lhes, interessar-lhes e interessá-los, obedecer-lhes e obedecê-los é flagrada com frequência em textos de autores com grande prática da escrita. E nem sempre isso se deve a alguma mudança na transitividade do verbo, mas à nossa falta de familiaridade com esses clíticos que não compuseram os dados primários a que fomos expostos na aquisição da nossa primeira gramática. $\mathrm{Na}$ falta de intuição, um ou outro serve!

Um exemplo interessante, que ilustra muito bem essa terceira gramática e nos mostra que não faz sentido eleger uma forma como melhor do que outra, está 
numa crônica de Luis Fernando Verissimo, publicada em O Globo em 2012, por ocasião do falecimento do jogador de futebol Sócrates. Ele começa sua crônica exatamente com o seguinte período:

"Nos cruzamos algumas vezes depois disso, mas a única vez que estive com o Sócrates foi na sua casa em Florença, quando ele era ídolo do Fiorentina."

E termina a crônica com um parágrafo assim iniciado:

"Sentamo-nos no quintal também e conversamos a tarde inteira."

Vejam que o autor usa o mesmo clítico com uma forma verbal trissílaba na primeira pessoa do plural do pretérito perfeito. No primeiro caso, faz uma colocação pronominal "proibida" pelos puristas (ou, no dizer impressionista dos gramáticos, "informal")! No segundo faz uma colocação considerada "exemplar" - usando um pronome enclítico, à moda lusitana, que acaba por produzir um vocábulo proparoxítono, forma evitada mesmo entre os letrados mais formalistas! O que nos resta fazer? Dizer que o autor começou errando e acabou acertando? Que ele passou de "informal" para "formal"? Que ele ora foi "inadequado" e depois se "adequou"? Ou que sua gramática é exatamente aquela a que Kato (2005) se refere? A mistura da colocação pronominal característica da sua L1 com aquela aprendida via escolarização e contato com a leitura ilustra perfeitamente o que é a gramática do letrado brasileiro ${ }^{7}$. Aliás, este autor, que é um modelo de escrita contemporânea, é pródigo em usos de pronomes reflexivos tônicos com formas nominativas, já plenamente implementados na fala e agora se inserindo na escrita (ele só se preocupa com ele mesmo em vez de consigo mesmo); na troca do clítico acusativo pelo dativo e vice-versa, acima mencionada, entre muitos outros traços que bem ilustram essa gramática do letrado brasileiro. Isso significaria que não se deve ensinar gramática na escola? Não! Mas que gramática ensinar? Onde encontrar uma descrição dessa gramática do letrado brasileiro, que sirva de parâmetros aos manuais escolares? ${ }^{8}$

\subsection{CONSIDERAC̣ÕES SOBRE O ENSINO DE PORTUGUÊS}

Não podemos fechar os olhos para a imperiosa necessidade de uma descrição da gramática da escrita contemporânea, reunindo os resultados de que já dispomos para servir de base a essa descrição plural. Já temos uma Gramática do Português Brasileiro, de Ataliba de Castilho (2010) e uma Gramática Pedagógica do Português Brasileiro, de Marcos Bagno (2011), que colocam em primeiro

\footnotetext{
Relendo este capítulo, vejo que a mesma mistura ocorre no meu texto escrito; algumas vezes ela é intencional; outras, completamente casual.

8 Um convite à tentativa de sistematizar a gramática do letrado brasileiro se encontra em Duarte (no prelo). Ali se enfatiza essa necessidade e se mostra o quanto já temos feito nessa direção.
} 
plano a descrição e a valorização da língua que falamos. Precisamos agora reunir os resultados com base em dados efetivos da escrita contemporânea, sem excluir ou condenar esta ou aquela forma (fazer isso seria incorrer no mesmo erro do passado), sem negar que essa escrita é variável, que essa variação está nos nossos artigos acadêmicos, nas teses e dissertações que orientamos, nos textos dos meios de comunicação escrita mais prestigiados do país.

É claro que nos falta reconhecer esse fato. Nos falta a consciência de que formar um bom leitor significa expô-lo a toda essa variação. E falta igualmente que a maioria dos autores de livros didáticos se dê ao trabalho de se informar sobre esses resultados e deixe de considerar que a variação linguística só existe no léxico e no que eles chamam de sotaques regionais ao se referirem às diferenças na prosódia. ${ }^{9}$ A leitura de Faraco (2008) é indispensável a quem deseja conhecer uma reflexão realista e ponderada sobre o tema. O autor chama a atenção para a absoluta inutilidade de manter os modelos conservadores dos primeiros gramáticos. Além de discorrer com o profundo conhecimento que ele tem sobre as razões que levaram à codificação das primeiras gramáticas, com os olhos voltados para um passado longínquo, o autor vê, claramente, que esse modelo não pode se perpetuar:

O modelo normativo anacrônico não causava maiores dificuldades enquanto o domínio da cultura letrada era problema de uma elite reduzida. Contudo, à medida que o acesso à escola se ampliou e o conceito moderno de cidadania, que inclui o direito de todos aos bens culturais, se propagou - esse modelo se tornou um problema grave, como no Brasil de hoje, em que ele não faz sentido para a maioria da população e acaba por embaraçar não só o ensino de português como o próprio funcionamento social da norma culta/comum/standard. (FARACO, 2008:146).

Não há dúvida de que o desenvolvimento de estudos desvendando as gramáticas do português brasileiro provocou de um lado uma série de comandos paragramaticais (como Pagotto (1998) se refere às colunas normativistas que assolam o país)! Chegamos a ver colunas em jornais de grande circulação nacional afirmando que nós, pesquisadores do CNPq, gastamos dinheiro público para ficar explicando erros! Para esses prestigiados colunistas "erro não se explica; corrige-se!”. Por outro lado, surgiu uma reação forte contra o preconceito linguístico, contra essa relutância em aceitar que nossa gramática não é o que alguns pensam

9 O único aspecto morfossintático abordado na maioria dos livros didáticos é a variação no uso de marcas de concordância, quase sempre tratada de maneira impressionista, equivocada e preconceituosa, quando distingue a fala culta e a popular com base numa presumível presença de marcas na primeira variedade e ausência na segunda, ignorando seu caráter extremamente variável e o crescente uso de marcas. 
que é ou gostariam que fosse; que eles, os normativistas de plantão, não falam como pensam que falam nem escrevem segundo as regras que apregoam.

A grande bandeira contra esse preconceito, sem qualquer embasamento teórico, foi levantada por Marcos Bagno, desde inícios dos anos 1990, e tem conquistado adeptos apaixonados, como Marta Scherre, e já alcançou os Parâmetros Curriculares Nacionais - qualquer manifestação de preconceito linguístico exclui uma coletânea candidata a adoção nas escolas públicas pelo $\mathrm{MEC}^{10}$. De fato, não pode haver nada mais triste do que dizer a um indivíduo que ele não sabe falar a sua língua; que aquela língua que ele usa desde que se entende por gente, para trabalhar, criar seus filhos, se comunicar com seus amigos, convencer um companheiro de alguma ideia, não é boa, é errada. Nada mais triste do que ouvir um indivíduo dizer que não sabe falar português ou que o português é uma língua muito difícil.

Encerro este capítulo lembrando que, antes de nos ajudar a entender essa realidade complexa que é o português brasileiro, a linguística nos ajudou a entender que a palavra - aqui traduzida por "a gramática nossa de cada dia" - é a ferramenta que nos torna humanos. E que a palavra do letrado não vale mais do que a daquele que não teve acesso a esta outra gramática, a da escola, que pode surgir na fala monitorada daqueles que têm suficiente prática e habilidade para fazer tal mudança, mas que fica, em geral, restrita à escrita, como mostram as pesquisas sobre a fala "culta".

Que aos alunos que cursam o segundo segmento do Ensino Fundamental seja levada uma gramática contemporânea; que as formas estranhas à fala mas já implementadas e recuperadas pela escrita sejam igualmente colocadas ao lado das que eles já dominam - como um acréscimo ao seu repertório! Para que isso seja viável, não podemos prescindir de uma descrição da escrita contemporânea a partir de resultados de pesquisas variadas, facilmente acessíveis àqueles que se dispõem a escrever um livro didático. Se isso não for feito, o descompasso entre o que se fala e o que se escreve (a distância já é bem menor do que sonham alguns "puristas"!) vai se perpetuar enquanto o estudo da gramática e o pleno desenvolvimento da escrita continuarão a ser um mistério para os alunos e para os jovens professores. (Sobre a recuperação de formas em extinção na fala e a implementação de formas inovadoras na escrita, ver, entre outros, os trabalhos publicados em Revista Linguística (2007), PAIVA; GOMES (2014), DUARTE (2012b); DUARTE (no prelo)).

10 A obediência a essa condição nem sempre é observada. Isso fica patente na atribuição às variedades populares de traços que são comuns a todas as variedades de fala brasileira, resultado da absoluta falta de interesse pela pesquisa realizada em todo o país e divulgada em um sem-número de publicações facilmente acessíveis. 
Depois dessa etapa, cabe aos livros didáticos e ao professor introduzir o aluno na gramática de outras sincronias - não no sentido de levá-lo a pôr em prática formas obsoletas, como a mesóclise, o pronome vós e todo o seu paradigma, mas para que ele possa entender e desfrutar dos textos literários do passado, com os quais terá de lidar ao longo de sua formação complementar.

\section{REFERÊNCIAS}

ABAURRE, M. B. (Org.). A construção fonológica da palavra: Gramática do português culto falado no Brasil. São Paulo: Contexto, 2013.

BAGNO, M. Gramática pedagógica do português brasileiro. São Paulo: Parábola Editorial, 2011.

BRAGA, M. L. Concordância de número do sintagma nominal no Triângulo Mineiro. Rio de Janeiro: PUC, 1978.

BRANDÃO, S. F. Patterns of agreement within the noun phrase. Journal of Portuguese Linguistics, v. 12, n. 2, p. 51-100, 2013.

. Variação e mudança no âmbito do vocalismo. In: MARTINS, M. A.;

ABRAÇADO, J. (Org.). Mapeamento sociolinguístico do português brasileiro. São Paulo: Contexto, 2015. p. 11-38.

BRANDÃO, S. F.; VIEIRA, S. R. Concordância nominal e verbal: contribuições para o debate sobre o estatuto da variação em três variedades urbanas do português. Alfa, v. 56, n. 3, p. 1035-1064, 2012.

CALLOU, D. Variação e mudança no âmbito do consonantismo. In: MARTINS, M. A.; ABRAÇADO, J. (Org.). Mapeamento sociolinguístico do português brasileiro. São Paulo: Contexto, 2015, p. 39-64.

CASTILHO, A. de. Nova Gramática do Português Brasileiro. São Paulo: Contexto, 2010. CHOMSKY, N. Lectures on Government and Binding. Dordrecht: Foris, 1981. . The Minimalist Program. Cambridge: The MIT Press, 1995.

CHOMSKY, N.; HALLE, M. The Sound Pattern of English. New York: Harper \& Row, 1968.

CUNHA, C.; SILVA, J. Variação entoacional nos enunciados interrogativos. In: MARTINS, M. A.; ABRAÇADO, J. (Org.). Mapeamento sociolinguístico do português brasileiro. São Paulo: Contexto, 2015. p. 79-108.

DUARTE, M. E. L. A perda do princípio "Evite Pronome" no português brasileiro. Tese (Doutorado) - Universidade Estadual de Campinas, Campinas, 1995.

DUARTE, M. E. L. A evolução na representação do sujeito pronominal em dois tempos. In: PAIVA, M. C.; DUARTE, M. E. L. (Org.). Mudança lingüística em tempo real. Rio de Janeiro: Contra Capa: Faperj, 2003. p. 115-128.

DUARTE, M. E. L. (Org.). O sujeito em peças de teatro (1833-1992): estudos diacrônicos. São Paulo: Parábola editorial, 2012a. 
DUARTE, M. E. L. Sobre o ensino da gramática nos níveis Fundamental e Médio: por que, quando e como? Revista Matraga, v. 19, n· 30, p. 41-60, 2012 b.

. O papel da Sociolinguística no (re)conhecimento do português brasileiro Revista LETRA, UFRJ, v. 1, p. 15-30, meio digital, 2013a.

. O papel da sociolinguística na descrição da gramática da escrita contemporânea. In: MARTINS, M. A.; TAVARES, M. A. (Org.). Contribuições da Sociolinguística e da Linguística Histórica para o ensino de língua portuguesa. Natal: Ed. da UFRN, 2013b. p. 117-143.

- Avanços no estudo da mudança sintática associando a Teoria da Variação e Mudança e a Teoria de Princípios e Parâmetro. Cadernos de Estudos Linguísticos, Campinas, v. 57, n. 1, p. 85-111, 2015.

. Para uma nova descrição da sintaxe do "português padrão". Cadernos de Letras da UFF, v. 25, n. 51, p. 23-41, 2016.

DUARTE, M. E. L.; FREIRE, G. C. Como a escrita padrão recupera formas em extinção e implementa formas inovadoras. In: PAIVA, M. C.; GOMES, C. A. (Org.). Dinâmica da variação e mudança na escrita. Rio de Janeiro: ContraCapa, 2014. p. 115-135.

DUARTE, M. E. L.; RAMOS, J. Variação nas funções acusativa, dativa e reflexiva. In: MARTINS, M. A. et al. (Org.) Panorama Sociolinguístico do Português Brasileiro: teoria, descrição e análise. São Paulo: Contexto, 2015. p. 173-195.

DUARTE, M. E. L.; SERRA, C. R. Gramática(s), ensino de português e “adequação linguística”. Revista Matraga, v. 22, n. 36, p. 31-55, 2015.

FARACO, C. A. Norma culta brasileira: desatando alguns nós. São Paulo: Parábola Editorial, 2008.

GOMES, C. A. Arquitetura da gramática e variação linguística na abordagem dos modelos multirrepresentacionais. Interdisciplinar, v. 17, p. 13-24, 2013.

HORA, D. da; CHRISTIANO, E. (Org.). Estudos Linguísticos: realidade brasileira. João Pessoa: Ideia, 1999.

HALLE, M. Phonology in generative grammar. Word, n. 18, p. 54-72, 1962.

ILARI, R. (Org.). Palavras de classe aberta: gramática do português culto falado no Brasil. São Paulo: Contexto, 2014.

- Palavras de classe fechada: Gramática do português culto falado no Brasil. São Paulo: Contexto, 2015.

ILARI, R.; MOURA NEVES, M. H. (Org.). Gramática do português culto falado no Brasil: classes de palavras e processos de construção. Campinas: Ed. da Unicamp, 2008. v. 2.

JUBRAN, C.; KOCH, I. (Org.). Gramática do português culto falado no Brasil: a construção do texto falado. Campinas: Ed. da Unicamp, 2006. v. 1.

KATO, M. A. A gramática do letrado: questões para a teoria gramatical. In:

MARQUES, M. A. et al. (Org.). Ciências da linguagem: trinta anos de investigação e ensino. Braga: CEHUM, 2005. p. 131-145.

KATO, M. A.; NASCIMENTO, M. do (Org.). Gramática do português culto falado no Brasil: a construção da sentença. Campinas: Ed. da Unicamp, 2009. v. 3. 
- A construção da sentença: Gramática do português culto falado no Brasil. São Paulo: Contexto, 2015. v. 2.

KROCH, A. Reflexes of grammar in patterns of language change. Language Variation and Change, n. 1, p. 199-244, 1989.

LABOV, W. Principles of Linguistic Change. Cambridge: Blackwell, 1994.

LAVANDERA, B. Where does the sociolinguistic variable stop? Language in Society, v. 7, n. 2, p. 1971-1982, 1978.

LEITE, Y.; CALLOU, D. Como falam os brasileiros. Rio de janeiro: Zahar, 2002.

LEMLE, M.; NARO A. Competências básicas do português. Rio de Janeiro: Mobral/ MEC, 1977.

LIGHTFOOT, D. How to set parameters. Cambridge: MIT Press, 1991.

LOPES, C. A inserção de "a gente" no quadro pronominal do português: percurso histórico. (Tese de Doutorado) - Universidade Federal do Rio de Janeiro, Rio de Janeiro, 1999.

LOPES, C. A inserção de "a gente" no quadro pronominal do português. Frankfurt: Vervuert; Madri: Iberoamericana, 2003. v. 18.

LOPES, C.; CAVALCANTE, S. A cronologia do voceamento no português brasileiro: expansão de você-sujeito e retenção do clítico-te. Revista Linguística, Santiago, v. 25, p. 30-65, 2011.

LOPES, R. E. V. The production of subject and object in Brazilian Portuguese by a Young child. Probus, v. 15, n. 1, p. 121-144, 2003.

LUCCHESI, D. Lingua e sociedade partidas: a polarização sociolinguística no Brasil. São Paulo: Contexto, 2015.

MARTINS, M. A.; TAVARES, M. A. (Org.). Contribuições da sociolinguísitica e da linguistica histórica para o ensino de lingua portuguesa. Natal: EDUFRN, 2013.

MARTINS, M. A.; VIEIRA, S. R.; TAVARES, M. A. (Org.) Ensino de português e sociolinguística. São Paulo: Contexto, 2014.

MARTINS, M. A.; COELHO, I.; CAVALCANTE, S. Variação sintática e gerativismo. In: MARTINS, M. A.; ABRAÇADO, J. A. (Org.). Mapeamento sociolinguístico do português brasileiro. São Paulo: Contexto, 2015. p. 221-247.

MATTOS; SILVA, R. V. O português são dois: novas fronteiras, velhos problemas. São Paulo: Parábola Editorial, 2004.

MOLLICA, M. C. M. Estudo da cópia nas construções relativas em português. Dissertação (Mestrado) - Pontifícia Universidade Católica, Rio de Janeiro, 1977. MOTA, J. A.; CARDOSO, S. M. Variação fônica nas capitais brasileiras. In: MARTINS, M. A.; ABRAÇADO, J. (Org.). Mapeamento sociolinguístico do português brasileiro. São Paulo: Contexto, 2015. p. 65-78.

MOURA NEVES, M. H. de. Estudos funcionalistas no Brasil. Revista DELTA, v. 15, p. 71-104, 1999.

NARO, A. J.; SCHERRE, M. M. P. Estabilidade e mudança em tempo real: a concordância de número. In: PAIVA, M. C.; DUARTE, M. E. L. (Org.). Mudança linguística em tempo real. Rio de Janeiro: Contra Capa, 2003. p. 47-62. 
SILVA, G. O. e; SCHERRE, M. M. P. Padrões sociolinguísticos: análise de fenômenos variáveis do português falado na cidade do Rio de Janeiro. Rio de Janeiro: Tempo Brasileiro, 1996.

OMENA, N. P. de. Pronome pessoal de terceira pessoa: suas formas variantes em função acusativa. Dissertação (Mestrado) - Pontifícia Universidade Católica, Rio de Janeiro, 1978.

- A referência variável da primeira pessoa do discurso no plural. In: NARO, A. et al. Relatório final de pesquisa: Projeto Subsídios do projeto censo à educação. Rio de Janeiro, UFRJ, 1986. p. 286-319.

PAGOTTO, E. G. Norma e condescendência; ciência e pureza. Lingua e Instrumentos Linguísticos, v. 1, n. 2, 1998.

PAGOTTO, E. G. Sociolinguística. In: PFEIFFER, C. C.; NUNES, J.H. (Org.). Introdução às ciências da linguagem: Linguagem, História e Conhecimento. Campinas: Pontes, 2006. p. 49-72.

PAGOTTO, E. G. A norma da constituição e a constituição da norma no século XIX. Revista LETRA, Rio de Janeiro, n. 1, p. 31-50, 2013.

PAIVA, M. da C; DUARTE, M. E. L. Quarenta anos depois: a herança de um programa na linguística brasileira. In: WEINREICH, U; LABOV W; HERZOG, M. I. Fundamentos empíricos para uma teoria da mudança linguística. São Paulo: Parábola Editorial, 2006. p. 131-151.

PAIVA, M. C; GOMES, C. A. (Org.). Dinâmica da variação e mudança na escrita. Rio de Janeiro: Contra Capa, 2014.

REVISTA LINGUÍSTICA. Rio de Janeiro: UFRJ, 2007.

RIZZI, L. The new comparative syntax: principles and parameters of universal grammar. Cahiers Ferdinand de Saussure, n. 43, 1989.

RIZZI, L. A parametric approach to comparative syntax: properties of the pronominal system. In: HAEGEMAN, L. (Org.). The new comparative syntax. London: Longman, 1997. p. 268-285.

ROBERTS, I. Verbs and diachronic syntax. Dordrecht: Kluwer, 1992.

SCHERRE, M. M. P. A regra de concordância de número no sintagma nominal em português. Dissertação (Mestrado em ) - Pontifícia Universidade Católica, Rio de Janeiro, 1978.

SCHERRE, M. M. P. et al. Variação dos pronomes "tu" e "você". In: MARTINS, M. A.; ABRAÇADO, J. (Org.). Mapeamento sociolinguístico do português brasileiro. São Paulo: Contexto, 2015. p. 133-172.

SCHERRE, M. M. P.; DUARTE, M. E. L. Main current processes in morphosyntactic variation. In: WETZELS, L.; COSTA, J.; MENUZZI, S. The handbook of portuguese linguistics. Oxford: Wiley-Blackwell, 2016.

SILVA, V. L. P. Motivações funcionais no uso do sujeito pronominal: um estudo em tempo real. In: PAIVA, M.C.; DUARTE, M. E. L. (Org.). Mudança lingüística em tempo real. Rio de Janeiro: Contra Capa: Faperj, 2003. p. 97-114. 
TARALLO, F. Por uma sociolinguística românica paramétrica. Ensaios de Linguística, n. 13, p. 51-84, 1987.

TARALLO, F.; KATO, M. A. Harmonia trans-sistêmica: variação inter e intralingüística. In: Preedição, Campinas, n. 5, p. 315-353, 1989.

VIANNA, J. B. S; LOPES, C. Variação dos pronomes “nós” e “a gente”. In: MARTINS, M. A.; ABRAÇADO, J. (Org.). Mapeamento sociolinguístico do português brasileiro. São Paulo: Contexto, 2015. p. 109-131.

VIEIRA, S.; BAZENGA, A. Patterns of third person verbal agreement. Journal of Portuguese Linguistics, v. 12, n. 2, p. 7-50, 2013.

VOTRE, S. J. Aspectos da variação fonológica na fala dos analfabetos do Rio de Janeiro. (Tese de Doutorado) - Pontifícia Universidade Católica, Rio de Janeiro, 1978. WEINREICH, U.; LABOV, W.; HERZOG, M. Fundamentos empíricos para uma teoria da mudança lingüística. Tradução de Marcos Bagno. São Paulo: Parábola Editorial, 2006. 
